\title{
Pelatihan Financial Report Perusahaan Dagang Menggunakan Software MYOB Accounting pada SMK Hang Nadim Batam
}

\author{
ARGO PUTRA PRIMA ${ }^{1}$; RIO RAHMAT YUSRAN ${ }^{2}$ \\ ${ }^{1,2}$ Program Studi Akuntansi, Universitas Putera Batam \\ Jln. R. Soeprapto Muka Kuning Kota Batam \\ Email : argoupb@gmail.com
}

\begin{abstract}
One of the uses of technology in the field of education is the use of learning software. The Ministry of National Educatio in 2010 requires financial programs by using your own business mind software in special schools for Vocational High Schools (SMK). One of the software that can be used in the world of education is MYOB Accounting. Responding to this, many have included MYOB software in their learning curriculum. This service was carried out at SMK Hang Nadim Batam in students with accounting errors. The methods used in the service are lecture methods, practice methods, providing training in the form of examples or questions, deferring responsibility. Students are required to use MYOB Accounting in presenting company financial statements. This training produces students who can make financial reports starting from input for making financial reports. The company discussed is a trading company. so that students can make sales, purchase, inventory and expense transactions.
\end{abstract}

Keywords: Accounting software, MYOB, Financial Report

Pengembangan Teknologi Informasi dan Komunikasi (TIK) dalam pendidikan, merupakan suatu bentuk kepercayaan guru tentang peranan dari TIK sebagai alat pembelajaran. Salah satu pemanfaatan TIK dalam bidang pendidikan adalah penggunaan software pembelajaran. Kementerian Pendidikan Nasional (Kemendiknas) tahun 2010 mewajibkan uji kompetensi akuntansi dengan menggunakan software mind your own Bisnis diselenggarakan di sekolah-sekolah khususnya Sekolah Menengah Kejuruan (SMK). Salah satu software akuntansi yang serng digunakan dalam dunia pendidikan adalah MYOB. Menanggapi hal tersebut banyak sekolah yang sudah memasukkan software komputerisasi akuntansi MYOB dalam kurikulum pembelajarannya (Wulan, 2016:15). Hal ini dilakukan agar siswa terbiasa menggunakan program tersebut. MYOB Accounting adalah salah satu program computer akuntansi berbasis windows (Kuntoro, 2008).

Kegiatan dalam yang kami lakukan sebagai dosen yang melihat kebutuhan pasar atau perusahaan untuk para pencari kerja, dimana rata rata perusahaan menentukan standar untuk para pecari kerja dengan kemampuan salah satunya bisa menguasai dan membuat laporan keuangan, bisa komputer dengan aplikasi akuntansi yang terkomputerisasi dengan menguasai salah satu program akuntansi (MYOB, Zahir Acounting, dll). Batam yang mayoritas dikatakan kota industri dan surganya para pencari kerja, serta perusahaan yang mayoritas berhubungan dengan ekonomi,bisnis hal ini akan berkaitan dengan akuntansi dan komputer dalam pembuatan laporan keuangan. Untuk itu dalam mecari pekerjaan dikota batam dibutuhkan keterampilan atau skill yang lebih dari para pencari kerja yang mayoritas berpendidikan tamat sekolah menengah atas serta sejalan dengan kebutuhan perusahaan yang mayoritas mencari pekerja dengan kualifikasi bertamatan sekolah menengah atas yang memiliki multi skill atau pun keahlian khusus salah satunya menguasai akuntansi dan komputer.

Sesuai dengan visi dan misi Sekolah Menengah Kejuruan (SMK) pada umumnya ingin menghasilkan lulusan yang siap untuk menghadapi dunia kerja 
terutama di Kota Batam, hal ini sejalan dengan arah tujuan dimana batam sebagai daerah kota industri serta surganya para pencari kerja yang penuh dengan persaingan kerja bagi para pencari kerja Menurut (Suryani,2014:22) . Akan tetapi masih banyak ditemui siswa lulusan SMK akuntansi yang belum bisa mengoperasikan software akuntansi. Oleh karena itu, perlunya pembinaan siswa Sekolah Menengah Kejuruan (SMK) dalam hal ini pengabdi memilih Sekolah Menengah Kejuruan (SMK) Hang Nadim Batam program studi akuntansi tempat untuk melakukan pembinaan. Pengabdian yang kami lakukan ini berkaitan dengan cara, proses pencatatan, pelaporan keuangan akuntansi di perusahaan dengan menggunakan komputer dangan aplikasi MYOB. Pengabdian yang kami lakukan ini sejalan dengan bidang mereka dipendidikan menengah atas tersebut.

\section{METODE}

Berdasarkan identifikasi masalah di atas, agar memperoleh manfaat dari pengabdian ini, maka metode yang ditawarkan dalam pengabdian ini adalah sebagai berikut:

1. Metode ceramah, dimana pengabdi menyampaikan materi tentang fiturfitur yang ada pada MYOB dengan menjelaskan secara umum terhadap modul yang diberikan.

2. Metode praktek, dimana para siswa mengikuti arahan pengabdi sesuai dengan soal yang ada dimodul di computer masing-masing.

3. Memberikan latihan dalam bentuk contoh kasus atau soal

4. Metode tanya jawab, peserta pelatihan diberikan kesempatan untuk bertanya.

5. Setiap siswa menyimpan hasil pekerjaannya difolder yang telah ditentukan untuk diperiksa.

Perusahaan yang menjadi objek dalam pelatihan ini adalah perusahaan dagang. Perusahaan dagang adalah perusahaan yang kegitan utamanya adalah membeli dan menjual barang tanpa merubah barang tersebut (Rudianto, 2012) Dalam kegiatan ini membutuhkan beberapa peralatan seperti:

1. Komputer

2. Papan tulis

3. Spidol dan Penghapus

4. Infocus

5. Buku/ Modul

6. Alat Tulis

\section{HASIL}

Pelatihan MYOB Accounting yang dilaksanakan pada bulan Juli 2018 siswa SMK Hang Nadim Program Studi Akuntansi dilakukan selama 2 hari berturutturut yang beralamat di Jalan Pendidikan Blok Pasar Melayu No. 3, Kelurahan Bukit Tempayan, Kecamatan Batu Aji, Kota Batam. Tim pelaksana terdiri dari 2 orang dengan peran masing-masing, yaitu Argo Putra Prima, S.E., M.Ak. membawakan materi set up MYOB Accounting perusahaan dan Rio Rahma Yusran, S.E., M.Si. memberikan materi input data transaksi.

Dari hasil pelatihan melalui metode ceramah serta praktek yang difasilitasi oleh pihak sekolah di labolatorium komputer SMK Hang Nadim dengan pre test dan latihan yang diberikan setelah dipaparkannya materi kepada para peserta, maka dapat dilihat bahwa siswa sangat antusias dan semua peserta dapat mengikuti dengan baik. Para siswa menyimpan hasil pekerjaan mereka pada sebuah folder di komputer masing-masing. Dari hasil berupa laporan keuangan yang disimpan tersebut diperiksa oleh tim pelaksana sehingga dapat dilihat bahwa peserta dapat memahami dengan baik materi yang disampaikan karena terlihat dari hasil yag ditampilkan. Ada beberapa siswa yang mendapatkan hasil laporan keuangan yang belum sesuai diarahkan oleh pelaksana mengenai kesalahan yang dilakukan siswa tersebut pada saat input transaksi. 


\section{PEMBAHASAN}

Berdasarkan permasalahan yang telah diuraikan program pengabdian masyarakat kali ini akan melakukan pembinaan kepada siswa SMK Hang Nadim dengan pelatihan software akuntansi MYOB dalam penyusunan laporan keuangan. Dimana jenis perusahaan yang dipilih adalah laporan keuangan perusahaan dagang karena transaksi pada perusahaan dagang lebih komplek jika dibandingkan dengan perusahaan jasa.

Pelaporan Akuntansi dengan menggunakan MYOB ini lebih banyak digunakan perusahaan dan lebih mudah diterapkan bagi para pembuat laporan kuangan, sehingga para siswa dapat menggunakan pengoperasionalan sistim MYOB. Solusi ini kami terapkan dalam pemberian pembinaan penggunakan aplikasi komputer akuntansi menggunakan MYOB beserta contoh soal dan pembuatan laporan keuangan yang menggunakan komputer dengan aplikasi program menggunakan MYOB.

Kegiatan difasilitasi oleh pihak sekolah di labolatorium komputer SMK Hang Nadim dengan pre test dan latihan yang diberikan setelah dipaparkannya materi kepada para peserta, maka dapat dilihat bahwa siswa sangat antusias dan semua peserta dapat mengikuti dengan baik. Para siswa menyimpan hasil pekerjaan mereka pada sebuah folder di komputer masingmasing. Dari hasil berupa laporan keuangan yang disimpan tersebut diperiksa oleh tim pelaksana sehingga dapat dilihat bahwa peserta dapat memahami dengan baik materi yang disampaikan karena terlihat dari hasil yag ditampilkan. Kegiatan pelatihan dilakukan mulai dari set up awal data perusahaan mulai dari profil perusahaan, jenis usaha, membuat nama-nama akun yang digunakan, data pelanggan, pemasok, data persedian barang, saldo awal perusahaan, input transaksi serta laporan akhir. Kegiatan ini sama dengan kegiatan yang dilakukan Nurussama dan Mutiara (2016) Politeknik Palcomtech yang melakukan pelatihan MYOB kepada siswa SMEA Pembina.

\section{SIMPULAN}

Dari pembahasan diatas maka dapat dismpulkan bahwa kegiatan pelatihan software MYOB Accounting dilakukan untuk menambah pengetahuan siswa SMK Hang Nadim tentang penyajian transaksitransaksi keuangan berbasis komputer. Pelajaran MYOB sendiri sebenarnya sudah dipelajari oleh siswa SMK Program Studi Akuntansi didalam kelas, akan tetapi materi yang disampaikan oleh pelaksana pelatihan lebih lebih mendalam dengan memberikan kasus-kasus perusahaan dagang yang mungkin masih menjadi hal baru bagi siswa. Perserta yang mengikuti terdiri dari siswa kelas XII berjumlah 12 orang yang akan segera lulus. Dan diharapkan dapat bermanfaat bagi mereka, baik bagi yang melanjutkan ke Perguruan Tinggi maupun dipergunakan dalam dunia kerja nantinya. Karena Kota Batam sebagai wilayah industri yang terdapat banyak perusahaan, keahlian dibidang akuntansi sangat dibutuhkan dalam dunia bisnis.

\section{DAFTAR RUJUKAN}

Kuntoro,Agus. 2008.Aplikasi Dasar-dasar Komputer Akuntansi

Menggunakan MYOB Accounting. Yogyakarta: Andi.

Nurusama dan Mutiara. 2016. Pengabdian Masyarakat Politeknik Palcomtech Dalam Bentuk Pelatihan MYOB Kepada Siswa SMEA Pembina 1. LPPM Politeknik Palcomtech: Palembang.

Suryani, 2014. Komputer Akuntansi MYOB SMK Kompetensi Mengoperasikan aplikasi Komputer Akuntansi $M Y O B$ versi 18. Salemba Empat: Jakarta.

Rudianto.2012.Pengantar

Akuntansi.

Erlangga : Jakarta. 
Wulan, Dian sari dan Paidi,2016. Laporan

Keuangan Mengunakan MYOB versi 19.6. Salemba Empat.

www.apipudin.staff.gunadarma.ac.id 